\section{New products and focus on impression materials and periodontology}

\section{SMOOTH, PRECISE IMPRESSIONS IN TWO MINUTES}

GC has produced a range of impression materials that set in super-fast time with Exafast NDS.

The Exafast NDS family of addition cured silicones provide high quality, accurate and consistent impressions every time. Exafast NDS allows you to produce very smooth and highly precise impressions in only two minutes, thus improving your productivity and maximising the comfort of your patients.

GC Exafast Putty is an extremely fast setting putty material, ideally for use in the single step technique. In combination with other GC Exafast NDS materials its working time of 45 seconds and setting time of 2 minutes 15 seconds offers you the perfect combination of speed and precision.

The Exafast wash material is available in three viscosities to suit your preferred technique. All are supplied in cartridges for speed and ease of application. As the material sets so quickly there is less risk of distortion due to movement during the setting.

With a high degree of elasticity, excellent tear resistance and good dimensional stability, Exafast NDS ensures that your impressions are perfect every time.

Reader response number 50

\title{
INHIBIT THE PERIODONTAL DESTRUCTION PROCESS
}

Periodontitis is one of the most common causes of tooth loss in UK adults. With preventative dentistry at the heart of UK dentistry, Dentomycin is an effective adjunct to scaling and root planing.

Dentomycin has been shown to help produce significant improvements in periodontal pathogen counts and plaque index scores. The specially designed applicator makes directing the gel into the affected pockets simple, with no unpleasant aftertaste for the patient. The unique formulation binds to the surface of the tooth, slowly releasing its active ingredients over time.

When used in conjunction with scaling and root planing, Dentomycin has been shown to inhibit the periodontal destruction process, significantly reduce key periodontal pathogens and actively help in the healing process. Indicated for the treatment of moderate to severe chronic adult periodontitis, Dentomycin is a costeffective approach that achieves reliable results.

Reader response number 51

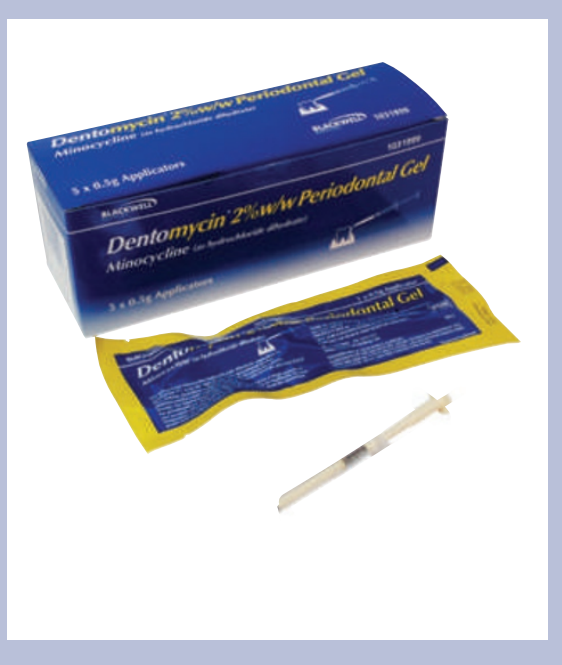

Please send trade news information and illustrations to Arveen Bajaj at the $B D J$, Nature Publishing Group, The Macmillan Building, 4-6 Crinan Street, London N1 9XW. Trade news is provided as a service to readers using text and images from the manufacturer, supplier or distributor and does not imply endorsement by the $B D J$. Normal and prudent research should be exercised before purchase or use of any product mentioned.

\section{MESSY IMPRESSIONS NO LONGER NEEDED}

Traditional time consuming and often messy impressions are no longer needed when you opt for the CEREC 3D CAD/CAM System.

As we all know, impressions are not always $100 \%$ accurate, which can result in costly remakes, and patients do not often enjoy the experience. The CEREC System takes an optical impression of the preparation and the antagonist, resulting in probably the most accurate impression you will ever have taken. To allow you complete control of the finished prosthesis you specify the positions of the margins and the proximal contacts. The CEREC system goes on to swiftly fabricate the crown, inlay, onlay or veneer accurately, quickly and to the very highest quality. CEREC automatically accurately computes the occlusal contacts, referring to the antagonist to do so resulting in the perfect fit.

The CEREC 3D CAD/CAM System will help you to produce probably the best ceramic restorations possible. You will find the fit to be superb as the margin for error has been removed, and the function, wear, durability and aesthetics of a CEREC prosthesis are second to none. In addition, this high-tech piece of equipment allows you to place the new prosthesis in the same visit, saving you and your patient time and laboratory fees and any embarrassment at having to wear a temporary whilst waiting for the final prosthesis to be fitted.

Reader response number 52 